\title{
Research on Mobile Communication Technology in the Internet+ Era
}

\author{
Shuxu Cao* \\ Yang Kai Technology Company, Foshan 528000, China. E-mail: caoshuxu@163.com
}

\begin{abstract}
With the continuous development of science and technology, although artificial intelligence has become the norm, if artificial intelligence science and technology are applied to mobile communications, it will be a huge technological leap. Some companies use artificial intelligence to analyze their faults and early warnings, so that they can effectively communicate between communications. This kind of contact method mainly relies on the analysis of personnel, and finds out the cause of the fault through network positioning, so as to realize the connection between the networks and the early warning of the communication network. By building system equipment to realize remote operation and control support communication, communication can be effectively realized.
\end{abstract}

Keywords: Internet+ Era; Mobile Communication Technology; Research

\section{Introduction}

With the rapid development of information technology, human society has entered the Internet+ era. In the Internet+ era, the field of mobile communications is also developing rapidly. The development of various mobile client terminals, short-term rental platforms and online car rental platforms have greatly improved people's quality of life. The development of mobile communication technology has gone through many stages. The most advanced is TD-LTE communication technology. This article analyzes the application status of mobile communication technology, hoping to provide reference for related research.

\section{The status quo of mobile communication technology}

With the innovation and rapid development of social technology, people have long been accustomed to the lifestyle of the era of big data. The advent of the big data era has brought great convenience to people's daily life and related production activities. In most technical fields, various new computer technologies and data computing technologies are usually integrated, which has a positive impact on social development and construction. With the gradual and in-depth development of social modernization and informatization, the requirements for Internet communication technology are getting higher and higher. In recent years, the design of communication hardware devices has gradually matured, and mobile communication base stations have been widely constructed. These infrastructure improvements have promoted the popularization of modern mobile communication technologies. In addition, with the continuous development of mobile communication technology, many common functions have been added. For example, adding artificial intelligence to communications can effectively achieve standardized management of the network. $4 \mathrm{G}$ once led the trend

This is an open-access article distributed under the terms of the Creative Commons Attribution Non-Commercial License (http://creativecommons.org/licenses/by-nc/4.0/), which permits unrestricted non-commercial use, distribution, and reproduction in any medium, provided the original work is properly cited. 
of the communication era, and now $5 \mathrm{G}$ is gradually spreading in most cities. As people's demand for networks continues to grow, after analyzing artificial intelligence failures, the application functions of communication technology also increase accordingly. For example, based on mobile operation and maintenance tools, through the reconstruction of the power grid early warning system, help the platform build more micro-applications and services, and ensure the safe operation of the network.

\section{Application of mobile communication technology in the Internet+ era}

\subsection{Smart home}

With the continuous development of artificial intelligence, in the information age, smart homes and application technologies have gradually entered people's lives. Many smart homes and electronic devices have appeared in the home, such as TV smart, air conditioning control and energy-saving lamps, electronic scales, water heaters, etc. Many commonly used electrical appliances are becoming more and more intelligent. These advancements have brought people a lot of convenience and promoted the development of people's smart life. With the rapid development of artificial intelligence, smart homes and their application technologies also appear in people's daily lives. Many smart homes and electronic devices have brought great convenience to people's lives, such as smart TVs, energy-saving lamps and heating. Many common household appliances, such as water dispensers, have also become intelligent, thereby promoting the intelligent development of people's lives. However, the smart home will be affected by many factors during the operation, and some failures may occur, which may cause safety hazards. As intelligence enters life, some problems arise. Some electronic devices often fail during work, and there are certain safety issues. Especially for some more complex electronic devices, hidden safety hazards may cause greater life threats to users. Therefore, in the case of frequent accidents, the early warning platform developed by technicians can remind people of related safety hazards. Through this early warning platform, you can use your mobile phone to connect to the smart home of the family, so that you can understand the working status of the family in real time and receive alarm notifications about dangerous situations. In addition, there are more instructions to directly control the smart home, which is conducive to the operation between the smart home and people. If you need to get high-quality hot water before going home, you can remotely execute the heating function of the water heater and keep it at a constant temperature before use. After going out and find that you forgot to turn off the air conditioner or other large electrical appliances, you only need to turn off the phone via the phone. It can be said that the remote control home system technology facilitates people's daily life and also facilitates the lives of most people. Mobile phones can solve many hidden safety hazards at home. For example, some complex electronic devices may have potential safety hazards due to environmental issues during operation, which may cause harm to users. Therefore, it is necessary to further develop an intelligent early warning platform and connect to a smart home through a mobile phone to understand its operating status. If they encounter a safety hazard, the early warning platform will issue an alert so that people can receive the danger alert in time.

\subsection{Multimedia communication}

With the rapid development of Internet technology, the types of mobile communication devices are gradually increasing, and people use communication devices to communicate more and more frequently. In recent years, many social software have been applied in people's daily life. Due to the development of the Internet, technology is constantly updated. As there are more and more types of mobile communication devices, people have realized communication through communication devices, thereby improving their communication skills. Use Weibo, WeChat, QQ and other social software for multimedia communication, not only can transfer pictures, voice calls, file transfers and video connections, but also can effectively monitor the location of old devices through the smart system background, providing people with different lifestyles. It's fun. It brings people a different feeling of life and increases the joy of life. Multimedia communication not only enriches people's daily life, but also enriches the information dissemination channels of power mobile communication equipment. People can use communication devices on the basis of artificial intelligence 
to realize information sharing and information transmission to meet people's information needs. Multimedia communication not only plays an important role in life, but also provides a channel for information dissemination for power mobile communication equipment. On the basis of artificial intelligence, by constantly updating communication equipment, we can find market needs that meet people's daily needs. After resource sharing, a resource early warning platform can be established in the background of the communication equipment for real-time monitoring to achieve better information transmission.

\subsection{Mobile office}

Artificial intelligence also has many applications in enterprises. When enterprises are engaged in management work, they usually send employees on business trips, and also need to perform tasks such as remote offices and meetings. In the process of enterprise development, mobile communication technology is also widely used. During the production and operation of the company, employees often travel on business, and at the same time they need to open offices in different places. During this period, employees have no fixed office locations. A series of complex office problems have emerged. During this period, because they are not in a fixed office location, they may cause problems such as office complexity. In order to solve this problem, various online office software has been developed. These office software have the characteristics of easy operation and strong applicability, which can greatly improve the efficiency and quality of the office work of traveling employees, and can encourage employees to stay active. The working attitude promotes the company's good development. In the Internet + era, mobile devices not only have functions such as multi-person collaborative office, rapid assistance, information transmission, information statistics, etc., so that work is no longer restricted by space, but also has many auxiliary functions. Office functions, such as scheduled offices and reminders, have improved the level of office informatization. Therefore, some online office software came into being. These online office software is convenient and fast, suitable for online office operations, can improve the efficiency and quality of employees in remote offices, help them maintain work enthusiasm, and improve the company's overall competitiveness. Nowadays, not only can writing, data transmission, information statistics and multi-person collaborative office work be completed quickly on mobile devices, but work is no longer restricted by time and space. In addition, office auxiliary functions have emerged, such as event reminders, regular office work, etc., which greatly improves the operability of the office. At the same time, business travel may cause a large amount of manpower to be mobilized, but the application of artificial intelligence can help companies effectively solve the problem of manpower shortage, promote the establishment of enterprise management system platform, and reduce manpower waste. These softwares can be completely built on smart phones and can complete office tasks without a computer. Data transmission through mobile communication equipment can not only effectively save office time, but also facilitate user reception, so as to coordinate and complete the office reasonably. When users receive messages and tasks, the intelligent system will send out reminders and notifications to help users deal with work problems in a timely and effective manner. The interconnection of the back-end system and communication equipment can effectively realize smart office and improve the efficiency of mobile office. In addition, corporate employees need to consume a lot of manpower and material resources during their business trips. Artificial intelligence can effectively solve the problem of insufficient staff. Companies can prevent wasting human resources by establishing a modern management system platform, and can install software. In a smart phone, it is easy to carry. In addition, during work, the system will automatically remind users when they receive messages or tasks, which can help users deal with problems in a timely manner.

\subsection{Online learning}

In the Internet+ era, the application of mobile communication technology makes various learning software appear in people's field of vision. The corresponding learning software can be installed in the smart phone, and learners can also download various learning content independently according to their own learning situation. Data can enable people to learn anytime and anywhere, greatly enriching people's learning content and improving learning effects. In practice, TD-LTE technology can also be used for distance teaching and online classroom teaching. Teaching resources can be 
transmitted, stored and shared through the client, cloud, etc., to achieve the purpose of improving the quality of education.

\subsection{Financial securities}

In the Internet+ era, the application of mobile communication technology has also brought about tremendous changes in the financial securities industry. With the help of data encryption algorithms such as MD5, the stability, security and convenience of mobile devices can be ensured when transferring financial securities data. At present, there are many mature financial securities software on the market, such as Huashun, Oriental Fortune, etc. Users can use smart phones to manage accounts, understand financial product information, credit card information, and use software to inquire about funds. Processes, credit card loan records, etc., are intelligent and personalized. In addition, users can also use the functions of smartphone software to open securities accounts and simulate stock transactions for stock and securities transactions, which greatly promotes the development of the financial industry, promotes the construction of Internet finance, and provides users with financial information channels.

\section{Conclusion}

In the Internet+ era, mobile communication technology and smart phones also promote each other and develop together. The rapid popularization of the Internet has also led to the development of various mobile intelligent terminal software, which has greatly improved people's daily life, work and study. With the improvement of people's quality of life, the requirements for mobile communication functions are gradually increasing. In this case, it is necessary to further increase the research on mobile communication technology in the context of Internet+ to meet the needs of all parties.

\section{References}

1. Cao Y, Hong H. Application status of mobile communication technology in the Internet+ era (in Chinese). China New Telecommunications 2019; (8): 96.

2. Jiang J, Lv L, Deng H. Analysis of the application status of mobile communication technology in the Internet+ era (in Chinese). Computer Programming Skills \& Maintenance 2019; (9): 57-58, 85.

3. Li J, Liu W, Fan L. Application status of mobile communication technology in the Internet+ era (in Chinese). Electronic Technology \& Software Engineering 2017; (22): 30.

4. Li D. Innovative research on college moral education in the era of "Internet Plus" [PhD thesis]. Wuhan: Central China Normal University; 2017. 